\title{
Assessment of Mental Burden of Family Caregivers of Persons with Health Disabilities in the Czech Republic
}

\author{
Zuzana Truhlarova ${ }^{1,2} \mathbb{D}$, Ondrej Stech ${ }^{1}$, Alena Voseckova ${ }^{1}\left(\mathbb{D}\right.$, Blanka Klimova $^{3}(\mathbb{D}$ \\ and Kamil Kuca $1, *$ (D) \\ 1 Faculty of Arts, University of Hradec Králové, Rokitanského 62, 50003 Hradec Králové, Czech Republic; \\ zuzana.truhlarova@uhk.cz (Z.T.); ondrej.stech@gmail.com (O.S.); alena.voseckova@uhk.cz (A.V.) \\ 2 Faculty of Education, University of Hradec Králové, Rokitanského 62, \\ 50003 Hradec Králové, Czech Republic \\ 3 Faculty of Informatics and Management, University of Hradec Králové, Rokitanského 62, \\ 50003 Hradec Králové, Czech Republic; blanka.klimova@uhk.cz \\ * Correspondence: kamil.kuca@uhk.cz
}

Received: 11 April 2020; Accepted: 4 June 2020; Published: 8 June 2020

\begin{abstract}
The purpose of this study was to analyse the subjective perception of stress burden in family caregivers, especially those caring for disabled and elderly persons. The tool for quantifying the burden was the Meister questionnaire, which describes the basic dimensions of overload in ten items. These were divided into three factors: overload, monotony and the non-specific factor. The research tool was a standardised questionnaire distributed via a snowball method to a group of 484 family caregivers who cared for a person with disability. The findings show that they have to largely rely on the support of social services. Their burden is characterised by the prevalence of the overload factor. The findings also indicate that there is an urgent call among health professionals to identify and treat caregivers' psychological distress by applying relevant intervention strategies, which could reduce this distress and prevent caregivers' burnout. Future research should concentrate on the efficacy of intervention strategies which would reduce the overall burden of family caregivers and nurture the family as a whole.
\end{abstract}

Keywords: subjective burden; family caregivers; distress; Meister questionnaire

\section{Introduction}

This study focuses on the topic of the caregiver's burden-the stress, subjectively perceived by family caregivers as a result of the care they provide to disabled persons. At present, a significant social pressure is pushing forward the processes of the deinstitutionalisation of the care provided to the disabled persons, in particular, the initiatives which allow the disabled persons to live in a natural family environment.

Under these circumstances, the support provided to the family caregiving system and the caregivers themselves turns out to be a highly important topic. Under the term "family caregivers of the disabled persons", we understand people providing care to family members who themselves cannot fulfil their needs. Those family members may be the caregiver's wife/husband, parent, child, or sister/brother. This kind of caregiving generates stressful situations caused not only by the demanding caregiving activities (treatments, education, personal assistance, organizing free time activities, etc.), but also by a strong feeling of commitment and responsibility for the family member they are taking care of.

Under certain conditions, caregiving for a disabled person may even induce the burnout syndrome in the caregiver. Typical negative phenomena observed in the families where the family caregiving is 
provided include changes related to the unequally distributed burden, the disabled person's perception of their own dependence on the caregiver, the caregiver's prioritisation of the disabled person's needs over their own and others. All these stress factors may negatively affect the caregiver's equilibrium and lead to the changes of their perception and behaviour (Pearlin et al. 1990; Schulz and Sherwood 2008; Bendová 2011; Steinlin et al. 2016).

The stress level can be measured in three basic dimensions, which mingle and mutually influence each other: the physical, metal, and somatic stress. All these kinds of stress are observed as a part of the caregiver's burden. We understand this subjectively perceived burden as an aggregate of various factors: family system, social services, or community system (Leggett et al. 2011; Pearlin et al. 1990; Kebza and Šolcová 2010).

This study focuses on the caregiver's burden as a problem affecting the quality of the direct caregiving effort.

Considerable attention has also been paid to the demands connected with the actual work activities. It turned out that highly stressful genic work was characterised by high demands for the quality, responsibility and dedication of the worker, together with a low autonomy of work activities. The autonomy of work activities represents the chance of the worker to decide on working pace, its nature and conditions (Židková 2002; Paulík 2009; Kebza and Šolcová 2010; Vosečková et al. 2013; Šavrnochová 2015).

In the case of family caregivers, especially the bio-psycho-social factors are the key factors which may have a significant impact on their overall quality of life (cf. Brodaty 2009; Lee and Singh 2010; Vosečková et al. 2015; or Turcotte 2015). The human body as a manifestation of existence in health, but equally in disease, in old age also in relation to handicap (mental as well as physical disability) with all its manifestations, examinations of various body cavities, bashfulness, shyness, questions concerning clients' and their families' very private affairs all fall among these factors. Caregivers often get in contact with recipients' emotions in difficult situations-vulnerability, loneliness, helplessness, loss, abuse, or death. They can be expressions of sadness, despair, anger, aggression and similar emotions which the recipient sometimes unconsciously turns against the social worker. Gratitude from the client's side or from other members of the family may thus not correspond to the endeavour and effort exerted by the caregiver. A specific problem of recent times is a role conflict in which the caregiver often has to perform as a manager or an administrator and concurrently as one who, in accordance with their attitude, provides the best care (Boumans and Dorant 2014; DePasquale et al. 2016, 2017). Recently, there has been an increase in clients' and family members' distrust, readiness for court review and search for a "culprit". The role of conflict gives rise to situations where certain requirements from the client's side cannot be met without simultaneously at least partially harming the family and, on the other hand, some demands of the family are not easy to meet unless the profession is harmed. The role of conflict is especially observed in women-who are the most involved in this type of care (Cho et al. 2011; Marešová et al. 2015; Truhlářová et al. 2015).

The daylong burden falls among the non-specific stressing factors, sometimes together with long-term sleep deprivation, obligation to decide in lack of thorough information, time requirements and requirements for continuous education and for adaptation to new situations and new approaches, requirements stemming from cooperation with experts of different professions (medical doctor, nurse, or supporting staff). Interpersonal problems arising within the family system fall among the very significant burdening factors. The cooperation of family members is obviously worsened by circumstances, such as exhaustion, conflict of interest and rivalry, or financial problems.

The non-specific stressing factors are the irregular character of the work (sudden worsening of somatic condition, depression, dependence on care), financial matters and the abundance of administrative tasks associated with social services (Hoefman et al. 2011; Marešová et al. 2016). That is why the purpose of this study was to analyse the subjective evaluation of the caregivers' burden. This factor is taken into consideration here, since not only the objective ratings are derived directly from the degree of disability, but also the subjective feeling of (un)bearability and long-term 
(un)manageability of the caregiving considerably contribute to the potential emergence of the burnout syndrome (Pearlin et al. 1990; Paulík 2009; Kebza and Šolcová 2010; Vosečková et al. 2013).

The partial objectives were as follows:

A-Evaluation of the perceived burden from the perspective of the home caregiver about a person with a health disability.

B-Identification of the key factors subjectively perceived by the family caregivers as most stressful.

C-Identification of the kind of disability evaluated by the caregivers as the most stressful to handle.

\section{Methodology}

\subsection{Design of the Study}

Two research tools were chosen for the processing of data collection: our original questionnaire and the Meister questionnaire for measuring mental stress.

\subsubsection{Original Questionnaire}

This questionnaire was designed to obtain data about the caregiver, the person who was cared for and the care itself. The person who was cared for was required to fill in their age, the type and degree of disability, to what extent they are able to perform individual life necessities (10 categories defined by the Ministry of Labour and Social Affairs, always evaluated on five point scale, the more points the less the person is able to procure the particular necessity), the degree of disability (categories I to IV according to Ministry of Labour and Social Affairs (MoLSA) — and category 0 for a control file consisting of parents caring for children with disability). The following data about the caregiver were collected: age, gender, education, occupation, religious belief, relation to the person cared for. Regarding the care itself, the following data were collected: the time duration of the care, the care venue, the number of persons in the household and social services currently used. As an additional question, the caregivers were asked to localise the subjectively perceived level of mental stress on a scale from 0 to 100 . Each questionnaire was filled by the caregiver.

\subsubsection{The Meister Questionnaire}

The Meister questionnaire (Sinclair 1975; Židková 2002) was chosen as the research tool which serves to evaluate the influence of work activities on workers' psychology. The author of the questionnaire is W. Meister from Zentralinstitut für Arbeitsmedizin in Berlin, who created it in 1975. In the years 1976-1984, the questionnaire was put to proof by hygienic services in the Czech Republic. The questionnaire is notable for its conciseness and understandability for respondents. Another of its advantages is its good reliability (Hladký and Židková 1999). The questionnaire was tested for reliability by Cronbach Alpha statistics. The overall value is 0.931 , which points to the very high reliability of individual items as well as the whole research tool.

The Meister questionnaire comprises 10 closed questions, each of which corresponds to a given burdening domain, see Table 1 which displays the Meister questionnaire indicators of stress; the questionnaires items; and the categories ( $\mathrm{N}=10$ items). The evaluation of the items was done using a five-grade Likert type scale ranging from number 1-"no, I do not agree at all" to 5-"yes, I fully agree". Respondents encircle the value which best corresponds to their feelings and impressions.

\subsubsection{Evaluation Method for Meister Questionnaire}

The Meister questionnaire can be evaluated in two ways:

- In function of individual items using critical value

- In function of factors (Overload, Monotony, Non-specific Factor). 
Table 1. The indicators of stress according to the Meister questionnaire. Questionnaire items: categories ( $\mathrm{N}=10$ items).

\begin{tabular}{cccc}
\hline Item No. & Burdening Domain & Item No. & Burdening Domain \\
\hline 1 & Time pressure & 6 & Monotony \\
2 & Low contentment & 7 & Nervousness \\
3 & High responsibility & 8 & Mental satiation \\
4 & Mind-numbing work & 9 & Exhaustion \\
5 & Problems and conflicts & 10 & Long-term bearability \\
\hline
\end{tabular}

Source: Hladký and Židková (1999).

\subsubsection{Evaluating Meister Questionnaire Items Using Critical Value}

As mentioned above, each item in the Meister questionnaire represents a burdening domain (see Table 1, Meister questionnaire indicators of stress and the questionnaires items, categories $(\mathrm{N}=10$ items)). In this method, a mean value is found for each item, calculated as the median for the whole respondent group. The mean values are then compared with critical values, which are stated in the questionnaire guidelines; when the determined value reaches or exceeds the critical value, respondents rate their work in the corresponding domain negatively. They rate it positively when the mean value does not reach the critical value (Hladký and Židková 1999).

Evaluating the analysis of the factors of the other method is the evaluation of the factors according to their function (overload, monotony, and non-specific Factor). It should be emphasised that Meister's questionnaire is a standardised tool. The factors were derived during the testing phase and they are now offered to the users of the questionnaire as a possible means of interpretation. Even a single individual could be evaluated in terms of factors. (see Table 2 which displays the factor structure of the questionnaire: the sum of items $(\mathrm{N}=10$ items $))$.

Table 2. The structure of the factors according to the Meister questionnaire: the sum of items ( $\mathrm{N}=10$ items).

\begin{tabular}{ccc}
\hline Factor & Factor Name & Sum of Items \\
\hline I. & Overload & $1+3+5$ \\
II. & Monotony & $2+4+6$ \\
III. & Non-specific Factor & $7+8+9+10$ \\
\hline
\end{tabular}

Source: Hladký and Židková (1999, p. 41).

Every item in the Meister questionnaire can be linked to one of the three factors of psychological work burden: overload, monotony and non-specific factor. The first factor, overload, is obtained by summing up items No. 1-time pressure, 3-high responsibility, 5-problems and conflicts. The second factor, monotony, is the sum of items No. 2-low contentment, 4-mind-numbing work, 6 -monotony. The third and last is the non-specific factor (stress response), represented by the sum of items No. 7-nervousness, 8-mental satiation, 9-exhaustion and 10-long-term bearability (Hladký and Židková 1999).

The totalled data can be subsequently used for the categorisation into degrees of psychological working burden. After finding the values of the arithmetic means of the factors, three possible cases can occur:

The first factor (overload) is by at least two points greater than the second factor (monotony). In this case, the first factor is added to third factor. The second factor (monotony) is by at least two points greater than the first factor (overload). In this event, the second factor is added to third factor.

The difference between the first and third factor is lower than two points. Then, the values of all three factors are summed up. 
The overall degree of burden can be used as an indicator of perceived stress and risk of burn-out.

\subsection{Data Collection}

The analysis of the subjective perception of a caregiver's burden was carried out on a sample of family caregivers. The study was approved by the Institute of Social Work, Faculty of Arts, University of Hradec Kralove, Czech Republic. All participants provided their consent with the survey. The research was conducted during the period of May 2015 until August 2016. A group of 484 family caregivers who cared for a person with disability participated in the research.

The questionnaires were distributed by trained interviewers in all regions of the Czech Republic.

The selection of the sample was judgmental, i.e., only the individuals who cared for a dependent person in their own domicile were included, irrespective of type of care provided.

The respondents specified the type of the disability of the person cared for (sensory disability, other physical disability, mental disability).

The data collection was carried out via the snowball method, in which some of the respondents, along with having filled the form in, provided contact for other caregivers or directly passed the questionnaire to them. By using this sampling method, it is not possible to get results that could be generalised for the whole population. However, in our circumstances, it was not possible to use the probabilistic sampling on this population, since there was lack of a sampling frame.

The questionnaires were collected by trained researchers, following the criteria set for the selection of respondents. The researchers informed the respondents about the anonymisation of the questionnaires and the confidentiality of the data collected (to be used for the specific research purposes only). The questionnaires were filled in on a paper sheet, in the presence of both the respondent and the researcher.

\subsection{Data Analysis}

The data were digitalised and processed through standard mathematical-statistical procedures, using the programs Excel and SPSS.

A-The first focused directly on the description of the perceived burden in the monitored group by the means of the Meister questionnaire, as described below. The questionnairee was evaluated in function of the factors of overload, monotony and non-specific factor, as specified below.

B-The second issue was how the total burden degree correlated with other items of the questionnaire which are briefly discussed in the following section. The burden was divided according to the evaluation methodology into three degrees: low, medium and high, with the latter posing a distinct risk of negative somatic impact.

After the identification of the factors perceived by the caregiver as the most stressful in relation to the type of the disabled person's handicap (sensory/other physical/mental disability, or the combination of more), the items of the Meister questionnaire and the types of the disabled persons' disabilities were subjected to the chi-square test of independence.

C-The third issue concentrated on the same problem from the viewpoint of factors-whether certain items influenced what type of burden the caregiver was going to perceive (see Table 2 displaying the Meister questionnaire indicators of stress; the questionnaires items; and the categories $(\mathrm{N}=10$ items)). It has to be remarked that the dominant stressing factor was not entirely independent on the degree of the perceived burden, as the evaluation method was such that the respondents with a low burden will show a non-specific factor because none of the factors are going to outweigh the others-see below the evaluation method.

\section{Results}

A group of 484 family caregivers participated in the research. The sex ratio was $386(79.8 \%)$ females and $98(20.2 \%)$ males. The age range of the respondents was between 18 and 85 years. The average age of the persons cared for was 48 years (range 1-98 years). The following evaluation of the research 
focuses at first on the overall evaluation of the burden in the whole group of caregivers for disabled persons. The Meister questionnaire was evaluated in terms of factors. The responses to the questions pertaining to individual factors show a rather high correlation (F1-F2: $\mathrm{r}=0.485 ; \mathrm{F} 1-\mathrm{F} 3: \mathrm{r}=0.607$; and F2-F3: $r=0.535)$, suggesting that the people experiencing a high burden perceive it overall throughout the whole spectrum. Naturally, this fact does not rule out the dominance of one factor over the others. Therefore, the first stage of the research concentrated in this area, as shown in Table 3.

Table 3. Evaluation in terms of the factors and the levels of stress.

\begin{tabular}{|c|c|c|c|}
\hline & \multicolumn{2}{|c|}{ Sum } & $\%$ \\
\hline Tendency toward overload & \multicolumn{2}{|c|}{259} & 53.5 \\
\hline Tendency toward monotony & \multicolumn{2}{|c|}{23} & 4.8 \\
\hline Combination & \multicolumn{2}{|c|}{202} & 41.7 \\
\hline Low burden & \multicolumn{2}{|c|}{200} & 41.4 \\
\hline Medium burden & \multicolumn{2}{|c|}{124} & 25.6 \\
\hline High burden & \multicolumn{2}{|c|}{160} & 33 \\
\hline & $\begin{array}{c}\text { Tendency toward } \\
\text { overload }\end{array}$ & $\begin{array}{l}\text { Tendency toward } \\
\text { monotony }\end{array}$ & Combination \\
\hline Low burden & $-2.8 /--$ & $0.2 / x$ & $2.7 /++$ \\
\hline Medium burden & $2.8 /++$ & $-0.9 / x$ & $-2.5 /--$ \\
\hline High burden & $0.3 / x$ & $0.6 / x$ & $-0.5 / x$ \\
\hline
\end{tabular}

Source: Author's computation. ${ }^{*}$ This table shows two types of results of the Meister Questionnaire. Overall significance of the chi-square independence test in this table is 0.025 . The values in the cells are adjusted standardised residuals. These symbols show the level of significance: $\mathrm{x}$ : no significance; $-/+: p<{ }^{*} 0.05 ;--/++: p<{ }^{* *} 0.01$; $---/+++: p<* * 0.001$.

It is apparent that caregivers perceive the overload significantly more than they perceive the monotony of caring; the tendency toward monotony is sporadic. In the group of caregivers for non-disabled persons, monotony is equally marginal; on the other hand, though, a combination of all factors, apart from the overload, dominates unequivocally, and the overall level of stress is markedly lower (by about $20 \%$ on average).

Furthermore, the group with low burden prevails, but the second to highest count comes forth in the group with the highest burden. Tables 4 and 5 illustrate that a higher burden occurs more frequently in persons with tendency toward the overload, while a combination of factors is typical for persons with a low burden (which, to a degree, is caused by the construction of the test). The occurrence of high burden, however, is comparable for all factors.

Table 4. Levels of stress.

\begin{tabular}{cl}
\hline Degree of Burden & \multicolumn{1}{c}{ Level of Stress } \\
\hline 1 & $\begin{array}{l}\text { Stress unlikely to influence health, subjective state and performance (at the } \\
\text { same time it is necessary to look away from random, situation-determined } \\
\text { fluctuations in the course of work shift). }\end{array}$ \\
\hline 2 & $\begin{array}{l}\text { Stress that may regularly temporarily negatively influence subjective state or } \\
\text { performance. }\end{array}$ \\
\hline 3 & Stress during which certain health risks cannot be ruled out. \\
\hline & Source: Hladký and Židková (1999, p. 42).
\end{tabular}

In the next phase, the correlation between the degree of burden and a range of variables which might relate to burden were analysed. The analysis scrutinised finer details, as only caregivers for disabled persons were selected from the whole set, which excluded the most distinct correlation given by the fact that the disability of the cared for person is the main burdening factor. 
Table 5. Chi-square test of independence between the burden and the individual variables.

\begin{tabular}{ccc}
\hline & Degree of Burden & Type (Factor) of Stress \\
\hline Physical disability of the person cared for (1) & 0.856 & 0.200 \\
Sensory disability of the person cared for (2) & 0.523 & 0.894 \\
Mental disorder of the person cared for (3) & 0.040 & 0.186 \\
Combination (1) + (2) & 0.332 & 0.348 \\
Combination (1) + (3) & 0.060 & 0.028 \\
Combination (2) + (3) & 0.125 & 0.546 \\
Combination (1) + (2) + (3) & 0.136 & 0.018 \\
\hline Daylong care & 0.012 & 0.695 \\
\hline Care duration & 0.389 & 0.466 \\
\hline Age of the person cared for & 0.116 & 0.023 \\
\hline Gender of the person cared for & 0.502 & 0.722 \\
\hline Use of social services & 0.019 & 0.292 \\
\hline Relation to the person cared for & 0.566 & 0.026 \\
\hline Number of children in the household & 0.070 & 0.079 \\
\hline Education of caregiver & 0.368 & 0.405 \\
\hline Age of caregiver & 0.839 & 0.255 \\
\hline Gender of caregiver & 0.313 & 0.055 \\
\hline Religion of caregiver & 0.561 & 0.851 \\
\hline
\end{tabular}

Source: Author's computation. * Values are the results of the chi-square independence test between the variables of the questionnaire and the results of the Meister Questionnaire. These results are in Tables 3 and 4. The significant values are commented upon in the text. This statistic was used, because most of the variables in our questionnaire are nominal.

In addition, the following variables were investigated in order to reveal individual correlations:

- Type of disability (physical, sensory, mental disorder);

- Daylong care or care while in employment;

- Duration of care;

- $\quad$ Age of the person cared for;

- Use of social services;

- Relation to the person cared for.

Other variables dealt in more detail with the characteristics of the caregiver:

- Gender;

- Education.

Overall, the results given in Table 5 show that the group caring for the disabled is quite homogeneous, without significant inner differentiation. However, a summarizing model of burdening factors can be created based on the observed correlations. The first column gives an overview of traits related to the degree of burden. These correlations suggest that caregivers for the mentally disabled, daylong-occupied caregivers and those who use social services to a greater extent, do also have a stronger inclination toward a higher burden. All these traits were derived from the character of the disability. Mental disorder is, on average, the most burdening one; furthermore, it requires, more than other types of disability, that the care be daylong. An analogous tendency is, to a lesser extent, also detectable in physical disability. Persons who make extensive use of social services are again those whose care is more demanding. The second column shows a correlation between individual factors and tracked variables. The combination of mental and physical disability can be observed to have an effect, and likewise so can combined disability-again, there is an influence of mental disorder. Where 
this combination appears, there is a characteristic perception of overload. Another two variables-age of the cared for person and relation them-are characterised by the fact that caregivers for their own child have a higher tendency toward overload, similarly to persons caring for children aged 5-18 years, the two facts obviously being related. It remains to briefly mention two more variables which are not statistically significant, but which show an apparent tendency. The first of them is the number of children: households with more children tend toward a greater burden, namely toward overload. The other is the caregiver's gender: caregiving women more often perceive overload whereas men, monotony; however, due to the low number of both men and persons perceiving monotony, this result should not be overly regarded.

\section{Discussion}

The aim of this research study was to discover how family caregivers perceive the workload associated with caring for a person with a disability, to identify what kind of disability the caregivers perceive as the most stressful within the workload. Our original questionnaire and the Meister questionnaire (Sinclair 1975; Židková 2002) for measuring mental stress was used to identify and evaluate the sources of work stress.

The findings show that caregivers perceive overload significantly more than they perceive the monotony of caring; tendency toward monotony is, so to say, sporadic. To compare, in the group of caregivers for non-disabled persons, monotony is equally marginal; on the other hand, the combination of all factors instead of overload dominates unequivocally, and the overall level of stress is markedly lower (by about $20 \%$ on average).

Caregivers for disabled persons are markedly more burdened with the care than those caring for healthy persons. This apparent influence outweighs all other, finer details. The findings of this study are consistent with a few other research studies in this field, e.g., Shah et al. (2010) or Turcotte (2015). The former research (Shah et al. 2010) shows that up to $90 \%$ of people with mental disorders are in the care of their relatives who provide them, with long-term practical and emotional support, which results in an inevitable exhaustion of caregivers with the burden in the form of emotional stress, depressive symptoms, or clinical depression. The overall caregiver stress burden was illustrated in the study by Pearlin et al. (1990).

Although family caregivers providing care for their own children are not as numerous as family caregivers, providing care for their older relatives (i.e., mother or father), the former seem to be much more burdened. As Turcotte (2015) indicates, this might be caused by their higher caregiving responsibilities, experiencing more serious psychological consequences, health effects, pressures on their personal finances and possible consequences in their career. In fact, these caregivers spend more hours on providing care, performing more tasks and more often are considered to be the primary caregivers by the recipients. For example, Turcotte (2015) states that $82 \%$ of regular caregivers who cared for their children felt worried or anxious due to their tasks and responsibilities; this was equally the case for $60 \%$ of those caring for their father or mother and $74 \%$ of those caring for their spouse.

The results show that family caregivers in the Czech Republic identify a significant stress burden based on the workload associated with caring for people with disabilities. The group of family caregivers of people with mental disabilities was identified as the most vulnerable group under stress.

The significance of the results is limited by various aspects of the methodology, i.e., the (A) sampling method, (B) sample size and (C) the research tools used. (A) The snowball method was used to collect the sample. This method is inherently biased by the character of the initial core of respondents. It is difficult to estimate the significance of the groups omitted or underreported by this method, especially since there is lack of representative studies across the Czech Republic. We can assume that the initial selection of respondents was biased with respect to age, education, region and the kind relation to the cared-for person, to name the most important ones. 
(B) The sample of 484 people is sufficient for the analysis of the general population, however, regarding the statistical analysis of the subgroups; some of them are too small to be meaningfully analysed. A bigger sample would be necessary for a more detailed insight into the problem.

(C) The research used a self-completion questionnaire. It is nonetheless limited by the lack of observational validation of the reported findings-respondents are free to fill the form without any supervision and they might be prone to stylisation, overrating recent experience, or might even wrongly asses their own situation (in some objective statements). This last point is, however, a minor limitation of this research.

Future research should concentrate on the efficacy of intervention strategies which would reduce the overall burden imposed on family caregivers.

\section{Conclusions}

The results of this study show that family caregivers perceive the worst psychosocial burden resulting from the workload associated with caring for people with mental disabilities. This can result in their complete exhaustion and thus burnout.

For this reason, appropriate strategies should be put into place to improve the quality of life of caregivers, which could reduce the psychological burden on caregivers in all bio-psycho-social-spiritual dimensions. Currently, there is insufficient psychosocial and mental support for this group of caregivers (Basaran et al. 2013; Nakigudde et al. 2016; or Valenti et al. 2016). In the literature, they suggest as an effective support the implementation of an intervention program for family caregivers training and educational activities that appear to be beneficial in reducing psychosocial anxiety, emotional and spiritual support, stress management methods, counselling and psychotherapy; cognitive-behavioural family interventions (Shah et al. 2010; Triantafillou 2010; Rezende Souza et al. 2017; Gharavi et al. 2018). Most recently, attention has been paid to the use of ICT in the implementation of this intervention and support focused on people with disabilities through their easy access and accessibility (Martinez-Alcar et al. 2016).

At our workplace, a comprehensive group program for home caregivers for health promotion (bio-psycho-social model) will be created and implemented in the context of reducing the overall burden with a focus on the issue of care for people with mental disabilities. Future research will focus on evaluating the effectiveness of intervention strategies that would reduce the overall burden on family caregivers with a focus on caring for people with mental disabilities.

Author Contributions: Conceptualisation, Z.T. and O.S.; methodology, A.V.; software, O.S.; validation, Z.T., B.K. and K.K.; formal analysis, B.K.; investigation, Z.T., A.V.; resources, Z.T.; data curation, O.S.; writing-original draft preparation, Z.T., O.S., A.V.; writing-review and editing, B.K., K.K.; visualisation, O.S.; supervision, Z.T. All authors have read and agreed to the published version of the manuscript.

Funding: It was supported by the long-term development plan of UHK.

Acknowledgments: This paper was supported by the project of Specific Research (grant UHK, ÚSP, Hradec Králové, No. 2015/2) Burnout syndrome in informal caregivers for a self-insufficient elderly person, as well as project Excellence 2018.

Conflicts of Interest: The authors declare no conflict of interest.

\section{References}

Basaran, Aydin, Kiymet Ikbal Karadavut, Ozden Sukran Uneri, Ozlem Balbaloglu, and Nazmi Atasoy. 2013. The effect of having children with cerebral palsy on quality of life, burn-out, depression and anxiety scores: A comparative study. European Journal of Physical and Rehabilitation Medicine 49: 815-22. [PubMed]

Bendová, Petra. 2011. Prevention of Communication Disorders in the Context of Cooperation between Family and Nursery School. In A Child in Family: Preschool and School Day-to-Day Reality. Torun: Wydawnictwo Adam Marszałek, pp. 288-99. 
Boumans, Nicolle G., and Elisabeth Dorant. 2014. Double-duty caregivers: Healthcare professionals juggling employment and informal caregiving. A survey on personal health and work experiences. Journal of Advanced Nursing 70: 1604-15. [CrossRef] [PubMed]

Brodaty, Henry. 2009. Family caregivers of people with dementia. Dialogues in Clinical Neuroscience 11: 217-28. [PubMed]

Cho, Eunhee, Nam-Ju Lee, Een-Young Kim, and Neville E. Strumpf. 2011. The Impact of Informal Caregivers on Depressive Symptoms Among Older Adults Receiving Formal Home Health Care. Geriatric Nursing 32: 18-28. [CrossRef]

DePasquale, Nicole, Kelly D. Davis, Steven H. Zarit, Phyllis Moen, Leslie B. Hammer, and David M. Almeida. 2016. Combining formal and informal caregiving roles: The psychosocial implications of double- and triple-duty care. The Journals of Gerontology. Series B, Psychological Sciences and Social Sciences 71: 201-11. [CrossRef]

DePasquale, Nicole, Couttney A. Polenick, Kelly D. Davis, Phyllis Moen, Leslie B. Hammer, and David M. Almeida. 2017. The psychosocial implications of managing work and family caregiving roles: Gender differences among information technology professionals. Journal of Family Issues 38: 1495-1519. [CrossRef]

Gharavi, Yasmin, Barbara Stringer, Adriaan Hoogendoorn, Jan Boogaarts, Bas Van Raaij, and Berno Van Meijel. 2018. Evaluation of an interaction-skills training for reducing the burden of family caregivers of patients with severe mental illness: A pre-posttest design. BMC Psychiatry [Online] 18: 84. [CrossRef]

Hladký, Aleš, and Zdeňka Židková. 1999. Methods of Evaluating Psychosocial Workload: Methodological Guide, 1st ed. Prague: Karolinum, (In Czech Language).

Hoefman, Renske J., N. Job A. Van Exel, Marleen Foets, and Werner B. F. Brouwer. 2011. Sustained informal care: The feasibility, construct validity and test-retest reliability of the CarerQol-instrument to measure the impact of informal care in long-term care. Aging \& Mental Health 15: 1018-27.

Kebza, Vladimír, and Iva Šolcová. 2010. Burnout syndrome, selected psychological variables and risk factors of cardiovascular diseases. Czechoslovak Psychology 52: 351-65, (In Czech Language).

Lee, Haejung, and Jagdip Singh. 2010. Appraisals, burnout and outcomes in informal caregiving. Asian Nursing Research 4: 32-44. [CrossRef]

Leggett, Amanda N., Steven Zarit, Angela Taylor, and James E. Galvin. 2011. Stress and Burden Among Caregivers of Patients With Lewy Body Dementia. Gerontologist 51: 76-85. [CrossRef] [PubMed]

Marešová, Petra, Alena Vosečková, Zuzana Truhlářová, and Kamil Kuča. 2015. Economic and Social Aspects of Informal Care for Alzheimer's Disease Patients in the Czech Republic. Paper presented at 2nd Central and Eastern European LUMEN International Conference on Multidimensional Education and Professional Development, Ethical Values (MEPDEV), Targoviste, Romania, November 17-19; pp. 17-19.

Marešová, Petra, Hana Mohelská, and Kamil Kuča. 2016. Social and family load of Alzheimer's disease. Applied Economics 48: 1936-48. [CrossRef]

Martinez-Alcar, Claudia I., Patricia Pliego-Pastrana, Alejandra Rosales-Lagarde, J. S. Lopez-Noguerola, and Eva M. Molina-Trinidad. 2016. Information and communication technologies in the care of elderly: Systematic review of applications aimed at patients with dementia and caregivers. JMIR Rehabilitation and Assistive Technologies 3: e6. [CrossRef] [PubMed]

Nakigudde, Janet, Byamah Brian Mutamba, William Bazeyo, Seggane Musisi, and Okello James. 2016. An exploration of caregiver burden for children with nodding syndrome (lucluc) in Northern Uganda. BMC Psychiatry 16: 255. [CrossRef]

Paulík, Karel. 2009. Moderators and Medicators of Stress Resilience, 1st ed. Ostrava: University of Ostrava, Faculty of Arts, (In Czech Language).

Pearlin, Leonard I., Josef T. Mullan, Shirley J. Semple, and Marilyn M. Kaff. 1990. Caregiving and the stress process: An overview of concepts and their measures. The Gerontologist 30: 583-94. [CrossRef]

Rezende Souza, Ana Lucia, Rezende Alves Guimarães, Daisy, De Araújo Vilela, Renata Machado De Assis, Lizete Malagoni De Almeida Cavalcante Oliveira, Mariana Rezende Souza, Dougles José Nogueira, and Maria Alves Barbosa. 2017. Factors associated with the burden of family caregivers of patients with mental disorders: A cross-sectional study. BMC Psychiatry [Online] 17: 353. [CrossRef]

Šavrnochová, Michaela. 2015. Alcohol Addiction in the Context of Family System. Banska Bystrica: Belianum. (In Slovak Language)

Schulz, Richard, and Paula R. Sherwood. 2008. Physical and mental health effects of family caregiving. American Journal of Nursing 108: 23-27. 
Shah, Aadil Jan, Ovais Wadoo, and Javed Latoo. 2010. Psychological distress in carers of people with mental disorders. BJMP 3: a327.

Sinclair, Marcus A. 1975. Questionnaire design. Applied Ergonomics 6: 73-80. [CrossRef]

Steinlin, Célia, Claudia Dolitzsch, Sophia Fischer, Klaus Schnech, Jörg M. Fegert, and Marc Schmid. 2016. The relationship between burnout symptoms and work satisfaction among child welfare workers in residential care. Praxis der Kinderpsychologie und Kinderpsychiatrie 65: 162-80, (In German Language). [CrossRef]

Triantafillou, Judy. 2010. Informal Care in the Long-Term Care System. European Overview Paper. Available online: http://interlinks.euro.centre.org/sites/default/files/WP5_Overview_FINAL_04_11.pdf (accessed on 21 February 2020).

Truhlářová, Zuzana, Jana Levická, Alena Vosečková, and Eva Mydlíková. 2015. Between Love and Duty—Care through the Eyes of Caregivers. Hradec Králové: Gaudeamus, (In Czech Language).

Turcotte, Martin. 2015. Family Caregiving: What Are the Consequences? Available online: http://www.statcan.gc. ca/pub/75-006-x/2013001/article/11858-eng.htm (accessed on 17 November 2016).

Valenti, Marco, Chiara DiGiovanni, Melania Mariano, Maria Chiara Pino, Vittorio Sconci, and Monica Mazza. 2016. Autism after an earthquake: The experience of L'Aquila (Central Italy) as a basis for an operative guideline. Epidemiologic Reviews 40: 49-52, (In Italian Language).

Vosečková, Alena, Zdeněk Hrstka, and M. Procházka. 2013. Handling stress in critical situations. In Hradec Králové Caregivers' Days Conference Proceedings. Hradec Králové: Nucleus, (In Czech Language).

Vosečková, Alena, Zuzana Truhlářová, and Ondřej Štěch. 2015. Burnout syndrome among social workers and informal caregivers working with elderly. Paper presented at the 2nd International Multidisciplinary Scientific Conference on Social Sciences and Arts SGEM2015, August 26-September 1; Book 1. vol. 1, pp. 333-40.

Židková, Z. 2002. The application of questionnaire in the evaluation of psychic load at work. Czech Journal of Occupational Medicine 3: 69-73, (In Czech Language).

(C) 2020 by the authors. Licensee MDPI, Basel, Switzerland. This article is an open access article distributed under the terms and conditions of the Creative Commons Attribution (CC BY) license (http://creativecommons.org/licenses/by/4.0/). 